\title{
Improving Global Kidney Health: International Society of Nephrology Initiatives and the Global Kidney Health Atlas
}

\author{
Adeera Levin \\ Department of Medicine, Division of Nephrology, University of British Columbia, Vancouver, BC, Canada
}

\section{Keywords}

Chronic kidney disease · Global health · Burden of illness ·

Clinical trials · Collaboration · Advocacy · Atlas · Care

\begin{abstract}
Background: Chronic Kidney Disease (CKD) is a major public health problem and is increasingly being recognized as an important driver of costs in all health care systems. The diversity of outcomes for people living with CKD is in part due to variability in biology, access to care, environmental factors, and health care system differences. The International Society of Nephrology (ISN), working in collaboration with its partners, has evolved into a philanthropic organization, from a traditional medical society, committed to a vision that sees "a future where all people have access to sustainable kidney health". A set of activities, including a Global Kidney Health Summit, the Global Kidney Health Atlas, and a Global Kidney Health Policy Forum, which has formed the
\end{abstract}

basis of a multi-stakeholder engagement process, building on a solid base of ISN programs and educational activities, is described. Through building awareness and increasing capacity to conduct research, the international community will build a more solid foundation on which to advocate for sustainable, ethical solutions to the problem of kidney disease throughout the world. Summary: The ISN aims to improve kidney health worldwide through a variety of diverse activities addressing education, advocacy, and research. Collaboration with partners within and outside the medical community is key in achieving this goal. Key Messages: Kidney disease is an important public health problem and is driven by genetic, environmental, and socioeconomic factors. Through active collaboration with diverse partners, the international community is striving for sustainable kidney health and aims to achieve this through coordinated work in a variety of spheres.

C 2018 The Author(s)

Published by S. Karger AG, Basel

\begin{tabular}{|c|c|c|}
\hline KARGER & $\begin{array}{l}\text { (๑) } 2018 \text { The Author(s) } \\
\text { Published by S. Karger AG, Basel }\end{array}$ & $\begin{array}{l}\text { Karger } \\
\text { Open access }\end{array}$ \\
\hline $\begin{array}{l}\text { E-Mail karger@karger.com } \\
\text { www.karger.com/anm }\end{array}$ & $\begin{array}{l}\text { This article is licensed under the Creativ } \\
\text { NonCommercial-NoDerivatives } 4.0 \text { Inter } \\
\text { NC-ND) (http://www.karger.com/Serv } \\
\text { Usage and distribution for commercial pu } \\
\text { tribution of modified material requires wr }\end{array}$ & $\begin{array}{l}\text { Commons Attribution- } \\
\text { ational License (CC BY- } \\
\text { es/OpenAccessLicense). } \\
\text { poses as well as any dis- } \\
\text { tten permission. }\end{array}$ \\
\hline
\end{tabular}

Adeera Levin, MD, FRCPC

Department of Medicine, Division of Nephrology University of British Columbia, St. Paul's Hospital 1081 Burrrard Street, Rm 6010A, Vancouver, BC V6Z 1Y6 (Canada) E-Mail alevin@ providencehealth.bc.ca 
Chronic Kidney Disease (CKD) is increasingly recognized as a public health problem worldwide [1-4]. The last 15 years has seen an increase in the awareness of $\mathrm{CKD}$, the heterogeneity of the condition, the variability in outcomes, and the impact of CKD as a multiplier of risk for other common conditions. Along with this increasing awareness, there have been multiple challenges and opportunities for the nephrology community. The International Society of Nephrology (ISN), through its diverse membership and activities, has played an important role in advocating for collaboration around important issues. This paper describes the current state of knowledge and activities in the area of CKD, the ISN vision and mission for the future, key activities documenting the state of current kidney health and care worldwide, and opportunities to improve the outcomes of patients living with CKD, through coordinated efforts, activities, and research endeavors.

CKD has been recognized as an important condition in multiple countries, through concerted efforts such as the World Kidney Day (www.worldkidneyday.org) and the Lancet Kidney Campaign (http://www.thelancet. com/campaigns/kidney). As a cause of years of life lost, CKD has moved from 25th (1990) to 21st (2005), and17th (2015) worldwide [5]. Furthermore, CKD has been cited as accounting for $1.38 \%$ of disability adjusted life years, with an annual growth of 1\% [6]. International estimates of CKD have been consistently between 10 and $16 \%$ of the adult population $[7,8]$, though there have been some reports of lower rates $[9,10]$. Estimates of prevalence have reported variability in different parts of the world $[8,11$, $12]$. In a 12 -country report involving over 75,000 persons, the prevalence of CKD was $14 \%$ among the general populations and 36\% among high-risk populations; in Europe, there are large differences between countries (e.g., $1 \%$ in central Italy) as compared to $6 \%$ in Northeast Germany [11], which are present after stratification for diabetes and hypertension. Diabetes and hypertension remain major drivers of CKD in most parts of the world, though there is increasing recognition that these conditions may amplify or alter the course of other intrinsic kidney diseases. This has not been systematically evaluated yet; however, as the prevalence of diabetes increases worldwide (estimates of 592 million people by 2035; www.intenationaldiabetesfederation.org), the implications for the prevalence of CKD are astounding.

The clinical problem facing us as $[9,10]$ global citizens is the various differences that exist in access to prevention and treatment, access to dialysis and transplantation, and access to trained health care professionals. Unfortunately,

Improving Global Kidney Health: ISN Initiatives and the GKHA most of the individuals with CKD globally do not have access to renal replacement therapies. A systematic analysis reported in the Lancet 2015 [13] by Liyange and colleagues estimates that between 27 and 53\% of patients needing renal replacement therapy (RRT) receive it, and thus between 2 and 7 million people in the world do not have access to RRT when reaching end-stage kidney failure. Furthermore, from an international perspective, there is variability in the prevalence and types of dialysis methods; even in lower-middle-income areas of the world, peritoneal dialysis (i.e., thought to be more "accessible" due to simplicity, lack of personnel costs, etc.) is not uniformly the RRT of choice. Environmental, social, and genetic factors play a role in access to care within and between countries [14-16]. There are recognized perverse incentives for dialysis modalities in many locations around the world, and many challenges prevail with regard to access to transplantation. Ethical approaches to dialysis and transplantation have been described in recent publications [17].

The ISN, founded in 1960 as a traditional medical society, has evolved over the last 50 years and has developed a broad set of activities, which are directed to meeting the new vision statement, "a future where all people have equitable access to sustainable kidney health". As a philanthropic organization, the ISN mission is to bridge the gaps of available care through advocacy and collaborations with global partners; build capacity of health care professionals through granting programs, education, and research; and connect with local, global, and professional communities to develop stronger understandings of the management of kidney diseases. The ISN recognizes that both Acute Kidney Injury (AKI) and CKD are global problems and challenging for all, and thus continue to build on programs and activities to work toward achieving the mission. In order to ensure better understanding of the spectrum of kidney diseases, building on the " 0 by 25 " AKI program [18], the ISN launched a series of additional activities including the first Global Kidney Health Summit [19-28], a Global Kidney Health Atlas (GKHA) [29, 30 and www.theisn.org/globalkidneyhealthatlas], as well as ISN Global Policy Forums.

The 2016 Global Kidney Health Summit brought together clinicians, researchers, translational scientists, industries, and others to identify and address gaps in care, policy, and research, and to develop a roadmap for the next 5-10 years. Summit participants represented all regions of the global community; identified the need to collaborate across multiple stakeholders; and established goals to improve our understanding of causes and patho- 
physiology of CKD of all etiologies, improve use of existing data sources, increase the evidence base for clinical care and decision making, and expand the clinical and research work forces. Participants also committed to a performance measurement framework to ensure accountability and transparency: a first for the international nephrology community.

The GKHA describes kidney care around the world, using the 6 dimensions of Universal Health Coverage as a framework for the survey [31-37]. One hundred and twenty-five countries were surveyed, representing 93\% of the world population using robust survey methodology, such that baseline data for all countries, regions, and the world could be presented. Country capacity, readiness, and response for optimal kidney care were assessed according to the 6 domains of Universal Health Care: health workforce, health service delivery, essential medicines and technologies, health financing, leadership, governance, and health information systems. Key findings included the vast variability of the nephrology workforce relative to population, with inverse proportions in lowand middle-income countries (LMIC) compared to highincome countries (HIC); lack of official registries for AKI, $\mathrm{CKD}$, dialysis, and transplantation in most parts of the world, and variation in health care services available for the identification of CKD by primary care (e.g., basic blood and urine tests are not available to many). Not surprisingly, diversity existed in the availability of dialysis services for acute and chronic conditions; even in those locations with availability, not all people had access to dialysis services due to economic, geographic, or other reasons. Health care system coverage varies around the world, with some countries having public, private, or combination services. Not all countries have basic medications (e.g., angiotensin converting enzyme inhibitor, blood pressure medications), and few have organized advocacy campaigns or policies addressing AKI or CKD. Furthermore, the capacity of research is limited to HIC, despite the large population base in LMIC and low-income countries. The GKHA describes for the first time, the current state of CKD care across low-income countries, LMIC, middle-income countries, HIC, and demonstrates inter- and intra-regional variability in current capacity for kidney care and important gaps in services, facilities, and workforce. There are key opportunities for engaging key governmental and nongovernmental stakeholders to support improving kidney care, and through use of a scorecard process, creates an accountability that will help with developing policy and changing practice over time, as part of the global health agenda.
The ISN Global Policy Forum, with a focus on Latin America, was held in April of 2017. It was co-hosted by the Health Ministry of Mexico, in collaboration with the journal The Lancet, and boasted international representation from Ministers of Health, the Pan American Health Organization, the World Health Organization, the United Nations Educational, Scientific, and Cultural Organization, clinicians, researchers, and scientists, as well as patient groups. The goal of the policy forum was to increase awareness regarding the magnitude of the problems within the region, to identify the changes required to impact the problem, and to develop collective commitment to change through the signing of a document by all participants $[38,39]$.

Through these various activities, we have identified that integrated approaches to kidney health are needed: better data from existing registries; organized work on the economic impact of kidney diseases on countries; collaboration with and outside of the health care profession; and better research activities across all pillars of basic, translational, clinical, and population research. If we commit to better understanding through descriptive studies (large cohort studies with biobanking, and longterm follow-up), well-designed physiological studies (to understand mechanisms of disease and interactions), and large clinical trials (with representative populations, simple and multiple interventions, reflective of complex disease processes), we may advance understanding and develop a more solid evidence base.

Paradoxically, the resources for the treatment of kidney diseases worldwide far outweigh the evidence base that informs clinical care: the investments by government and research funding bodies seem disproportionate to the expenditures on care. The ISN has committed to increasing research capacity through a number of distinct activities. To date, more than 81 clinical research grants have been awarded to LMIC; also iNET CKD (International Network for CKD Cohort studies; https://www. theisn.org/research/inet-ckd) has been launched [40]; and ISN Advancing Clinical Trials (https://www.theisn. org/research/isn-act) have been established [41] to enhance the capacity of all regions to conduct clinical trials, and to facilitate the cultural change necessary to promote clinical trials.

Through this integrated approach to improve kidney health (e.g., by educating, facilitating research activities of all types, mobilizing health care work forces, building alliances, and ensuring that policy and position statements can be clearly recognized), the international community in general, and the ISN in particular, are in a
Levin 
much stronger position to advocate for sustainable kidney health.

The ISN, with all of its partners and collaborators, is proud to be providing innovative approaches and solutions; measuring and documenting progress; and providing a strong voice focusing on kidney diseases around the globe.

While CKD is recognized as a public health problem, change is happening through collaborative activities such as basic science and translational consortia, patient-ori- ented research consortia, and collaborative clinical trials networks. This change, based on new knowledge, new paradigms, and new policies, has great potential to improve global kidney health.

\section{Disclosure Statement}

A.L. received travel expenses and registration fee from Danone Nutricia Research to attend the 2017 Hydration for Health Scientific Conference.

\section{References}

1 Eckardt KU, Coresh J, Devuyst O, Johnson RJ, Köttgen A, Levey AS, et al: Evolving importance of kidney disease: from subspecialty to global health burden. Lancet 2013;382:158169.

2 Jha V, Garcia-Garcia G, Iseki K, Li Z, Naicker S, Plattner B, et al: Chronic kidney disease: global dimension and perspectives. Lancet 2013;382:260-272.

3 Couser WG, Remuzzi G, Mendis S, Tonelli M: The contribution of chronic kidney disease to the global burden of major noncommunicable diseases. Kidney Int 2011;80: $1258-1270$.

4 GBD 2015 Disease and Injury Incidence and Prevalence Collaborators: Global, regional, and national incidence, prevalence, and years lived with disability for 310 diseases and injuries, 1990-2015: a systematic analysis for the global burden of disease study 2015. Lancet 2016;388:1545-1602.

5 GBD 2015 Mortality and Causes of Death Collaborators: Global, regional, and national life expectancy, all-cause mortality, and cause-specific mortality for 249 causes of death, 1980-2015: a systematic analysis for the global burden of disease study 2015. Lancet 2016;388:1459-1544.

6 GBD 2015 DALYs and HALE Collaborators: Global, regional, and national disability-adjusted life-years (DALYs) for 315 diseases and injuries and healthy life expectancy (HALE), 1990-2015: a systematic analysis for the Global Burden of Disease Study 2015. Lancet 2016; 388:1603-1658.

7 James MT, Hemmelgarn BR, Tonelli M: Early recognition and prevention of chronic kidney disease. Lancet 2010;375:1296-1309.

8 Hill NR, Fatoba ST, Oke JL, Hirst JA, O'Callaghan CA, Lasserson DS, et al: Global prevalence of chronic kidney disease - a systematic review and meta-analysis. PLoS One 2016;11:e0158765.

9 Benghanem Gharbi M, Elseviers M, Zamd M, Belghiti Alaoui A, Benahadi N, Trabelssi EH, et al: Chronic kidney disease, hypertension, diabetes, and obesity in the adult population of Morocco: how to avoid "over"- and “under"-diagnosis of CKD. Kidney Int 2016; 89:1363-1371.

10 Glassock RJ, Warnock DG, Delanaye P: The global burden of chronic kidney disease: estimates, variability and pitfalls. Nat Rev Nephrol 2017;13:104-114.

11 Brück K, Stel VS, Gambaro G, Hallan S, Völzke H, Ärnlöv J, et al: CKD prevalence varies across the European general population. J Am Soc Nephrol 2016;27:2135-2147.

12 Ene-Iordache B, Perico N, Bikbov B, Carminati S, Remuzzi A, Perna A, et al. Chronic kidney disease and cardiovascular risk in six regions of the world (ISN-KDDC): a cross-sectional study. Lancet Glob Health 2016;4: e307-e319.

13 Liyanage T, Ninomiya T, Jha V, Neal B, Patrice HM, Okpechi I, et al: Worldwide access to treatment for end-stage kidney disease: a systematic review. Lancet 2015;385:19751982.

14 Hao H, Lovasik BP, Pastan SO, Chang HH, Chowdhury R, Patzer RE: Geographic variation and neighborhood factors are associated with low rates of pre-end-stage renal disease nephrology care. Kidney Int. 2015;88:614621.

15 Gao S, Manns BJ, Culleton BF, Tonelli M, Quan H, Crowshoe L, et al: Access to health care among status Aboriginal people with chronic kidney disease. CMAJ 2008; 179: 1007-1012.

16 Evans K, Coresh J, Bash LD, Gary-Webb T, Köttgen A, Carson K, et al: Race differences in access to health care and disparities in incident chronic kidney disease in the US. Nephrol Dial Transplant 2011;26:899-908.

17 Jha V, Martin DE, Bargman JM, Davies S, Feehally J, Finkelstein F, et al: Ethical issues in dialysis therapy. Lancet 2017;389:1851-1856.

18 Mehta RL, Burdmann EA, Cerd J, et al: Recognition and management of acute kidney injury in the international society of nephrology 0by25 Global Snapshot: a multinational cross-sectional study. Lancet 2016;387:20172025.

19 Levin A, Tonelli M, Bonventre J, Coresh J, Donner JA, Fogo AB, et al: Global Kidney
Health 2017 and Beyond: A Roadmap for Closing Gaps in Care, Research, and Policy. The Lancet. 2017. http://thelancet.com/journals/lancet/article/PIIS0140-6736(17)307882/abstract (cited May 1, 2017).

20 Levin A, Eckardt KU, Tonelli M: The Global Kidney Health Summit Outputs: details to guide the nephrology community along the road to global kidney health. Kidney Int Suppl 2017;7:61-62.

21 Coresh J, Hu JR, Bello AK, Feldman HI, Fogo $\mathrm{AB}$, Ganji MR, et al: Action plan for determining and monitoring the prevalence of chronic kidney disease. Kidney Int Suppl 2017;7:6370.

22 Luyckx VA, Tuttle KR, Garcia-Garcia G, Gharbi MB, Heerspink HJL, Johnson DW, et al: Reducing major risk factors for chronic kidney disease. Kidney Int Suppl 2017;7:7187.

23 Jardine MJ, Kasiske B, Adu D, Alrukhaimi M, Ashuntantang GE, Basnet S, et al: Closing the gap between evidence and practice in chronic kidney disease. Kidney Int Suppl 2017;7:114121.

24 Obrador GT, Schultheiss UT, Kretzler M, Langham RG, Nangaku M, Pecoits-Filho R, et al: Genetic and environmental risk factors for chronic kidney disease. Kidney Int Suppl 2017;7:88-106

25 Pena MJ, Stenvinkel P, Kretzler M, Adu D, Agarwal SK, Coresh J, et al: Strategies to improve monitoring disease progression, assessing cardiovascular risk, and defining prognostic biomarkers in chronic kidney disease. Kidney Int Suppl 2017;7:107-113.

26 Bello AK, Alrukhaimi M, Ashuntantang GE, Basnet S, Rotter RC, Douthat WG, et al: Complications of chronic kidney disease: current state, knowledge gaps, and strategy for action. Kidney Int Suppl 2017;7:122129.

27 Pollock C, Zuk A, Anders HJ, Ganji MR, Johnson DW, Kasiske B, et al: The establishment and validation of novel therapeutic targets to retard progression of chronic kidney disease. Kidney Int Suppl 2017;7:130137.
Improving Global Kidney Health: ISN Initiatives and the GKHA
Ann Nutr Metab 2018;72(suppl 2):28-32 DOI: $10.1159 / 000488123$ 
28 Perkovic V, Craig JC, Chailimpamontree W, Fox CS, Garcia-Garcia G, Gharbi MB, et al: Action plan for optimizing the design of clinical trials in chronic kidney disease. Kidney Int Suppl 2017;7:138-144.

29 Bello AK, Levin A, Tonelli M, Okpechi IG, Feehally J, Harris D, et al: Assessment of global kidney health care status. JAMA 2017;317: 1864-1881.

30 Bello AK, Johnson DW, Feehally J, Harris D, Jindal $\mathrm{K}$, Lunney $\mathrm{M}$, et al: Global kidney health atlas (GKHA): design and methods. Kidney Int Suppl 2017;7:145-153.

31 Levin A: Building blocks toward sustainable kidney care around the world: results from a multinational survey by the international society of nephrology. Kidney Int Suppl 2018;8: 27-29.

32 Osman MA, Alrukhaimi M, Ashuntantang GE, et al: Global nephrology workforce: gaps and opportunities toward a sustainable kid- ney care system. Kidney Int Suppl 2018;8:5263.

33 Okpechi IG, Alrukhaimi M, Ashuntantang GE, et al: Global capacity for clinical research in nephrology: a survey by the international society of nephrology. Kidney Int Suppl 2018; 8:82-89.

34 Htay H, Alrukhaimi M, Ashuntantang GE, et al. Global access of patients with kidney disease to health technologies and medications: findings from the global kidney health atlas project. Kidney Int Suppl 2018;8:6473.

35 Bello AK, Alrukhaimi M, Ashuntantang GE, et al: Global overview of health systems oversight and financing for kidney care. Kidney Int Suppl 2018;8:41-51.

36 Lunney M, Alrukhaimi M, Ashuntantang GE, et al: Guidelines, policies, and barriers to kidney care: findings from a global survey. Kidney Int Suppl 2018;8:30-40.
37 See EJ, Alrukhaimi M, Ashuntantang GE, et al: Global coverage of health information systems for kidney disease: availability, challenges, and opportunities for development. Kidney Int Suppl 2018;8:74-81.

38 Conclusions of Mexico City - Latin America unites against Kidney Disease|The Lancet Kidney Campaign. http://www.thelancet.com/ campaigns/kidney/updates/conclusions-ofmexico-city (cited November 30, 2017).

$39 \mathrm{http} / / /$ ish-world.com/news/a/ISN-GlobalKidney-Policy-Forums/.

40 Dienemann T, Fujii N, Orlandi P, Nessel L, Furth SL, Hoy WE, et al: International network of chronic kidney disease cohort studies (iNET-CKD): a global network of chronic kidney disease cohorts. BMC Nephrol 2016; 17:121.

41 Levin A, Remuzzi G: Clinical trials: ISNACCTS: global initiatives to improve clinical research. Nat Rev Nephrol 2014;10:426-427. 